\title{
Helping Teens Answer the Question "Who Am I?": Sexual Development in Adolescents ${ }^{1}$
}

\author{
Rosemary V. Barnett and Sally A. Moore ${ }^{2}$ \\ This publication is the fifth of a series that \\ explores adolescence in terms of physical, cognitive, \\ social, moral, gender, and sexual development. This \\ publication will focus on the sexual development that \\ adolescents experience.
}

The journey from childhood to adolescence is very challenging. Between the ages of 10 and 17 there are major changes in physical, cognitive, social, and moral development. The major task for adolescents is to establish their self-identity. By determining - as best they can - a sense of who they are, they attempt to move into a group that reflects or reinforces this self-identity. The group allows them to feel that they stand out from the crowd. This phase of development allows the adolescent to search for their sense of self. This is in order to answer the increasingly important question that they could not consider in earlier stages of development: "Who am I?"

\section{Sexual Development}

Of the important decisions facing adolescents, those relating to sexuality and sexual activity are some of the most significant. Even adolescents who choose not to engage in sexual activity must attend to this area of development. Indeed, "...regardless of their sexual behavior status, most youth engage in protracted struggles concerning a multiplicity of questions about their development of sexual beings" (Shoveller et al, 2004). In order to ensure the emotional, psychological, and physical safety of adolescents, it is vital for the adults who care about and work with them to understand sexual development and be aware of current trends in adolescent sexual behavior.

Sexual development in adolescents begins with the biological changes that come with puberty. As discussed in Helping Teens Answer the Question "Who am I": Physical Development in Adolescents (Barnett, 2005), puberty begins between the ages of eight and fourteen years old and includes physical growth, enlargement of the genitals, development of pubic and underarm hair, as well as facial hair in boys, and breast growth in girls. These changes not only signify that biologically adolescents are now sexually mature, but also they are associated with surges in sexual interest.

1. This document is FCS2296, one of a series of the Department of Family, Youth and Community Sciences, Florida Cooperative Extension Service, Institute of Food and Agricultural Sciences, University of Florida. Original publication date March 2009. Visit the EDIS Web site at http://edis.ifas.ufl.edu.

2. Rosemary V. Barnett, Ph.D, Associate Professor of Family, Youth and Community Sciences, and Sally Moore, M.S., Alumni Fellow in School Psychology, College of Education; University of Florida; Gainesville 32611. 
Although the biological changes associated with puberty, especially the increase in testosterone levels, allow for the occurrence of sexual activity, other factors in an adolescent's life interact with them to make sexual expression either more or less likely (DeLamater \& Friedrich, 2002). Such influential factors are present throughout adolescents' environments, occurring at the individual level (intellectual ability, drug use), familial level (parental monitoring, family structure, socio-economic status), extrafamilial level (involvement in committed relationship, school attachment, peer group, quality of neighborhood), and macrosystem level (cultural values, state/federal policies, sexual education) (Small \& Luster, 1994). Often, the information adolescents receive about sex can be confusing and contradictory (Berk, 2006). They may hear from parents and educators that they should abstain from sexual activity, while simultaneously receiving messages from the media and their peers that encourage sexual exploration.

Adolescents face several developmental tasks, including those related to gender identity and sexual orientation, as they experience their development as sexual beings. The development of gender identity involves the internalization, or not, of social gender roles and is discussed in Helping Teens Answer the Question "Who am I": Gender Development in Adolescents (Barnett \& Bates, In Press 2009). Sexual orientation refers to who an individual is emotionally and physically attracted to, and is generally categorized as heterosexuality, homosexuality, or bisexuality. Another important task is the maintenance of intimate relationships, both physical and emotional. The successful undertaking of this task is affected by gains in cognitive and social development.

\section{Trends in Adolescent Sexual Behavior}

\section{In 2005, 46.8\% of American adolescents} reported ever having sexual intercourse and 33.9\% reported being currently sexually active, the latter being defined as having had sex at least once in the past three months (CDC, 2005). Additionally, 6.2\% of adolescents surveyed had sex for the first time before the age of thirteen and $14.3 \%$ of adolescents surveyed reported having four or more lifetime sexual partners.

Previous research has noted a typical progression in sexual behaviors from kissing to petting to sexual intercourse to oral sex (Feldman, Turner, \& Araujo, 1999). This sequence has been identified for both males and females. A recent study, however, found that college students reported that they had both performed and received oral sex at an earlier age than when they had engaged in sexual intercourse (Moore, Barnett, Brennan, \& Gibson, 2007). In this study, the mean age of sexual debut was 17.19 , while the mean age at which respondents first performed oral sex was 16.83 and the mean age at which they first received oral sex was 16.88. Again, results were similar for males and females. This finding is consistent with research suggesting that oral sex is becoming increasingly common among adolescents (Prinstein, Meade, \& Cohen, 2003; Remez, 2000).

\section{Tips for Parents, Extension Agents, and Youth Workers}

Now that we have a sense of some of the important physical changes that occur during adolescence, we can use this information to help us better understand teens. It will also help us recognize their sensitive thoughts and feelings. And we can use it to help us direct them toward positive behavior and outcomes.

One of the most important things Extension agents and parents can do to ease the process of sexual development is to remember that it is completely normal. The author of a recent article on adolescent sexual development stresses that, "In short, sexual development, as the result of interactive processes, must be conceptualized as normative and as shaped by multidimensional and complex forces" (Porter, 2002, p. 403). Adults who live or work with adolescents should avoid treating sexual thoughts or actions as negative risk behaviors, as this ignores the myriad factors that contribute to sexual development.

Parents and youth workers can help adolescents make safe and healthy choices regarding sexual behavior by maintaining open lines of communication and ensuring access to appropriate 
information and resources. By talking to their adolescents about sex, parents can make sure that their values and opinions are heard and can hope to better understand what their children and thinking and feeling about sex. It is important that adolescents receive complete and accurate sexual education so that they can make better informed decisions about their own sexual desires and activities.

\section{References}

Barnett, R. \& Bates, S. (In Press). Helping Teens Answer the Question "Who Am I?": Gender Development in Adolescent and Emerging Adult Males. EDIS [on-line]. University of Florida Institute of Food and Agricultural Sciences.

Barnett, R.V. (2005). Helping Teens Answer the Question "Who Am I?": Physical Development in Adolescence (FCS2240). University of Florida Institute of Food and Agricultural Sciences.

Retrieved February 27, 2009 from http://edis.ifas.ufl.edu/FY770.

Berk, Laura E. (2006) Child Development, 7th Edition. Boston, MA: Allyn and Bacon.

Centers for Disease Control and Prevention (CDC). (2005). Healthy Youth! Youth Risk Behavior Surveillance System: Comprehensive Results, Sexual Behaviors. Retrieved July 3, 2007 from http://apps.nccd.cdc.gov/yrbss/ CategoryQuestions.asp?Cat $=4 \&$ desc $=$ Sexual $\% 20$ Behaviors.

DeLamater, J., \& Friedrich, W. (2002). Human sexual development. The Journal of Sex Research, 39(1), 10-14.

Feldman, S., Turner, R., \& Araujo, K. (1999). Interpersonal context as an influence on sexual timetables of youths: Gender and ethnic effects. Journal of Research on Adolescence, 9(1), 25-52.

Moore, S., Barnett, R., Brennan, M., \& Gibson, H. (2007). Sexual timetables of adolescents: The recent trend of early oral sex. Manuscript submitted for publication. University of Florida.
Porter, C. (2002). Female "tweens" and sexual development. Journal of Pediatric Nursing, 17(6), 402-406.

Prinstein, M., Meade, C., \& Cohen, G. (2003). Adolescent oral sex, peer popularity, and perceptions of best friends' sexual behavior. Journal of Pediatric Psychology, 28(4), 243-249.

Remez, L. (2000). Oral sex among adolescents: Is it sex or is it abstinence? Family Planning Perspectives, 32(6), 298-304.

Shoveller, J., Johnson, J., Langille, D., \& Mitchell, T. (2004). Socio-cultural influences on young people's sexual development. Social Science \& Medicine, 59, 473-487.

Small, S., \& Luster, T. (1994). Adolescent sexual activity: An ecological, risk-factor approach. Journal of Marriage and the Family, 56, 181-192. 